Document downloaded from:

http://hdl.handle.net/10251/66824

This paper must be cited as:

Albarracin, M.; Talens Oliag, P.; Martínez Navarrete, N.; González, RJ.; Drago, SR. (2016). Physicochemical properties and structural characteristics of whole grain Oryza sativa L. with different treatments. Food Science and Technology International. 22(4):1-10. doi:10.1177/1082013215600078.

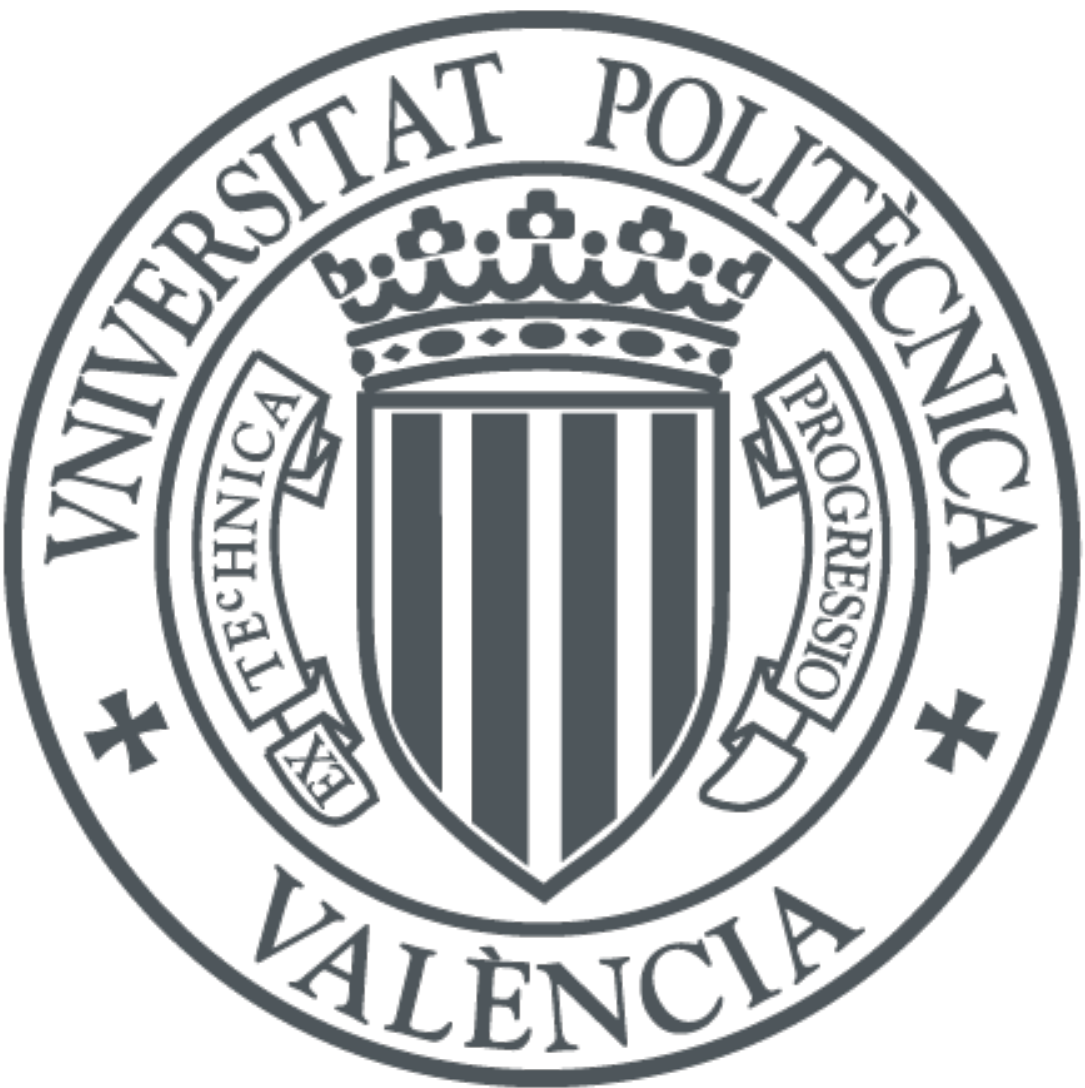

The final publication is available at

https://dx.doi.org/10.1177/1082013215600078

Copyright Sage

Additional Information 


\title{
PHYSICOCHEMICAL PROPERTIES AND STRUCTURAL CHARACTERISTICS OF WHOLE GRAIN Oryza sativa L. WITH DIFFERENT TREATMENTS
}

\author{
Micaela Albarracín ${ }^{1,2}$, Pau Talens ${ }^{3}$, Nuria Martinez-Navarrete ${ }^{3}$, Rolando J. González ${ }^{1}$ and \\ Silvina R. Drago ${ }^{1,2 *}$
}

${ }^{1}$ Instituto de Tecnología de Alimentos, Facultad de Ingeniería Química, Universidad Nacional Del Litoral, Santiago del Estero 2829, (3000) Santa Fe, Argentina;

${ }^{2}$ Consejo Nacional de Investigaciones Científicas y Técnicas (CONICET), Argentina;

${ }^{3}$ Departamento de Tecnología de Alimentos, Universitat Politècnica de València, Camino de Vera s/n, 46022 Valencia, España.

*Author to whom correspondence should be addressed:

Telephone: 54 -342- 4571164 (int. 2585).

E-mail: sdrago@fiq.unl.edu.ar 


\begin{abstract}
Physicochemical properties and structural characteristics of whole rice flours with different treatments (soaking, germination and extrusion cooking) were studied. Water solubility (WS), water absorption (WA), crystallinity, adsorption isotherms (BET and GAB models) and glass transition temperature $(\mathrm{Tg})$ of the samples were determined. WS and WA were enhanced by extrusion cooking process (3.17-4.98 vs. $24.1-53.76 \mathrm{~g} / 100 \mathrm{~g}$ and $2.77-3.05 \mathrm{vs}$. $4.46-7.04 \mathrm{ml} / \mathrm{g}$, respectively), but crystallinity was decreased (30-33 vs. 4-16\%). Adsorption isotherms showed that extruded samples exhibited higher equilibrium moisture content as compared with their corresponding non extruded samples (5.0-19.2 vs. 4.0-16.1g water/g solids). There were no changes in $\mathrm{Tg}$ values in the studied moisture range $(3.8-16 \mathrm{~g} / 100 \mathrm{~g})$. These results allow the correctly use of whole rice flours with different treatments in foods and also contributed to the knowledge of stabilization of the products.
\end{abstract}

Keywords: whole rice, soaking, germination, extrusion cooking, adsorption isotherms, glass transition temperature. 


\section{Introduction}

Rice (Oryza sativa L.) is one of the major cereal crops and a staple food for the world's population. Compared to white rice, brown rice (WG's: whole grains) is nutritionally superior, rich in dietary fiber, antioxidants, protein, minerals, and vitamins. All of these compounds are present in the bran layers and germ (Jones \& Engleson, 2010). Even though WG's consumption is recommended, the incorporation into the diet is low because of the lack of habits and difficulty to incorporate them into processed foods. Thus, research on food formulations is needed. Several traditional food-processing and preparation methods can be used to enhance the bio-accessibility of nutrients in plant-based diets. These include thermal processing, mechanical processing, soaking, fermentation, and germination/malting. These strategies aim to decrease the content of non nutritional components, such as phytates, or increase the bio-accessibility of micronutrients. Regarding that, Albarracín et al. (2015) showed 50\% and $77 \%$ reduction of phytates after soaking and soaking-extrusion, respectively. Also, a 50\% reduction of phytates was observed after germination-extrusion process (unpublished results). Extrusion cooking is a multi-stage unit operation that combines transport, mixing, working and forming. It has diverse applications, from de-polymerization of starch for ethyl alcohol fermentation to pet food production. It is a high-temperature short-time (HTST) process in combination with high mechanical shear, which makes it a good 'model' to analyze processing effect on product properties (González et al., 2002). The high shear forces and temperature during extrusion cooking severely affect biomacromolecules by breaking covalent bonds. Additionally, Maillard reactions may occur between reducing sugars and amino acids of proteins (Mercier, 1993).

To explain the behavior of food components during processing and storage, food structure should be considered as a natural system plasticized by water (Matveev et al., 2000). This interpretation provides a way to physically characterize the system and to determine safe storage conditions for each food. The physical, chemical and microbial changes in foods have conventionally been described using the concept of water activity $\left(\mathrm{a}_{\mathrm{w}}\right)$. It has provided a reliable 
estimation of microbial growth, lipid oxidation, non enzymatic and enzymatic activities, and the texture/mouthfeel of foods.

BET (Brunauer, Emmett and Teller) and GAB (Guggenheim, Andersen and De Boer) are typical water sorption models used for foods. The classical BET multilayer sorption equation is used to calculate monolayer values in very different physicochemical fields because of the simplicity of its application and due to it has the approval of the International Union of Pure and Applied Chemistry (IUPAC) (Timmermann, 2003). According to the GAB model, the sorption state of the sorbate molecules in the layers beyond the first one (monolayer) is the same but different to that of the pure liquid. The extra assumption of the GAB model over the BET formulation demands the introduction of the additional constant $\mathbf{k}$. This constant is just the measure of the difference of free enthalpy of the sorbate molecules in these two states, the pure liquid and this second sorption stage, the layers above the monolayer (Timmermann, 2003).

Moisture content changes during processing affect the thermal properties of a food system. Water is a very effective plasticizer and will reduce Tg. It is also known that when food structure is in the glassy state, shelf life is prolonged. Glass transition concept appeared as a powerful tool for understanding mechanisms of the processes controlling shelf life of food. The glass transition temperature (Tg) could be taken as a reference temperature, which is important when predicting the optimal conditions for drying, agglomeration, and storage (Roos \& Karel, 1991). At storage temperature (Ts) lower than $\mathrm{Tg}$, the molecular mobility is restricted and the food is stable, but at Ts higher than Tg, instability processes (physical, chemical and biological) would be controlled by the difference between $\mathrm{Ts}$ and $\mathrm{Tg}$.

The aim of this work was to study the effect of soaking, germination and extrusion cooking on water absorption, water solubility, crystallinity, adsorption isotherm and glass transition temperature of whole grain rice flours in order to analyze the changes on hydration properties and structural characteristics caused by the above processes.

\section{Materials and methods}




\subsection{Raw samples}

Rough and brown long rice Fortuna Type (Oryza sativa) were provided by Los Cerrillos S.A (Santa Fe, Argentina).

\subsection{Processed samples}

A total of six processed samples were studied: brown rice (BR), extruded brown rice (EBR), soaked rice (SR), extruded soaked rice (ESR), germinated rice (GR) and extruded germinated rice $(\mathrm{EGR})$.

2.2.1 Brown rice $(\boldsymbol{B R})$ : Brown long rice was provided dehulled by industry. Rice grains were grinded according to a diagram developed in our laboratory. It was done with a roller mill (Bühler-Miag, Braunschweig, Germany) in such a manner to avoid the production of too many fine particles (less $250 \mu \mathrm{m}$ ). Particle smaller than $420 \mu \mathrm{m}$ represented less than $3 \%$ but were included in the whole sample for extrusion cooking. A progressive and successive reduction in distance between rollers from 1 to 0.5 and $0.25 \mathrm{~mm}$ was used. After each grinding step, the flour was screened through $1.190 \mathrm{~mm}$ sieve. The thicker particles (> $1.190 \mathrm{~mm}$ ) were re-ground until the whole sample was obtained.

2.2.2 Soaked rice $(\boldsymbol{S R})$ : An amount of $3 \mathrm{~kg}$ of rough rice was previously washed in a $0.2 \%$ $\mathrm{NaClO}$ solution during 15 minutes and then soaked in a $5.5 \mathrm{~g} / \mathrm{L}$ lactic acid solution at $45^{\circ} \mathrm{C}$ for 24 h (Albarracín et al., 2015). After that, the grains were washed with tap water, dried to almost $13 \mathrm{~g} / 100 \mathrm{~g}$ moisture content using a tray dryer at $40{ }^{\circ} \mathrm{C}$, dehulled in a laboratory rice mill (Galicet, San Salvador, Entre Ríos, Argentina), and grinded to grits (1190 - $420 \mu \mathrm{m}$ particle size), as mentioned in 2.2.1.

2.2.3 Germinated rice (GR): An amount of $3 \mathrm{~kg}$ of rough rice was steeped in distilled water at $20^{\circ} \mathrm{C}$ during $24 \mathrm{~h}$. Then, the water was drained, and the moistened rice grains were germinated during $24 \mathrm{~h}$ by putting the rice in an oven at $35^{\circ} \mathrm{C}$ and $98 \%$ relatively humidity, according to the previous conditions studied. Finally, germinated rice was dried $24 \mathrm{~h}$ at $40{ }^{\circ} \mathrm{C}$, dehulled and grinded to grits (1190 - $420 \mu \mathrm{m}$ particle size), as mentioned in 2.2.1. 


\subsubsection{Extruded brown rice (EBR), extruded soaked rice (ESR), and extruded germinated rice}

$(\boldsymbol{E G R})$. Rice grits obtained in 2.2.1, 2.2.2 and 2.2.3 were conditioned to the adequate moisture (M) $1 \mathrm{~h}$ before each run and extruded with a Brabender 20DN extruder, using a 4:1 compression ratio screw, a 3/20-mm (diameter/length) die, and a screw speed of $150 \mathrm{rpm}$. The feeding rate of the extruder was at full capacity. While the extruder feeding section was maintained cool by circulating water through the jacketed device, the metering and die sections were both kept at the temperature corresponding to each run by using the heat control device of the extruder. The extrusion cooking conditions: $160{ }^{\circ} \mathrm{C}-14 \% \mathrm{M}$ for EBR; $160{ }^{\circ} \mathrm{C} 16.5 \% \mathrm{M}$ for ESR; $175{ }^{\circ} \mathrm{C} 14 \%$ M for EGR were selected according to preliminary studies (González et al., 2013a) taking into account good expansion, sensorial hardness and flavor.

\subsection{Analytical Methods}

All samples were ground using a Sample Mill Ciclotec (USA), with a $1 \mathrm{~mm}$ sieve.

\subsubsection{Composition}

Total nitrogen was determined by the semi micro Kjeldahl method (AOAC 920.53, 1999) using the value of 5.95 as nitrogen/protein conversion factor, according to Juliano (1985). Lipids (petroleum ether extract), moisture and ash contents were determined using AOAC (1999) approved methods. Total amount of fiber was determined by AOAC 985.29 method adopted by Megazyme ® commercial kit. Total starch (\%) was quantified according to Tovar et al. (1990). Glucose oxidase/peroxidase assay kit (Wiener Lab, Rosario, Argentina) was used for colorimetric determination of glucose, and concentration was determined at $505 \mathrm{~nm}$ using a spectrophotometer (Milton Roy Genesys 5, Ivyland, USA). Calculation of sample glucose concentration was done using a glucose standard. Available carbohydrates (d.b) were calculated by difference.

Free fatty acids (FFA) were analyzed according to Lowry and Tinsley (1976), previous extraction of the lipids with the Folch procedure. The results were expressed as mg lauric acid/g sample using a Lauric Acid standard calibration curve. 
Thiobarbituric acid reactive substances (TBARS) assay according to Siu and Draper (1978) was performed. Results were expressed as $\mu \mathrm{mol}$ of $\mathrm{MDA} / \mathrm{g}$ sample using the molar absorption coefficient of the malondialdehyde $\left(\mathrm{MDA}=0.156 \mathrm{mM} \cdot \mathrm{cm}^{-1}\right)$.

\subsubsection{Water absorption and water solubility}

Water absorption (WA), as spontaneous uptake of water, was determined using Baumman method according to González et al. (2002). About 50 mg of sample was spread on a filter paper, and the volume of absorbed water was measured after the equilibrium was reached (approximately 20 minutes). The result was expressed as $\mathrm{mL}$ water/g sample d.b.

Water solubility (WS) was evaluated by the method of Gonzalez et al. (2002). An aliquot of 1.25 $\mathrm{g}$ of ground sample was dispersed in $25 \mathrm{~mL}$ of water, stirred for 30 minutes and centrifuged at 2000xg for $30 \mathrm{~min}$ at $25{ }^{\circ} \mathrm{C}$. The supernatant was dried in an oven at $105{ }^{\circ} \mathrm{C}$ and the soluble solids determined by weight. The solubility was calculated as: $\mathrm{WS} \%=\mathrm{g}$ soluble solids $/ 100 \mathrm{~g}$ sample d.b.

\subsubsection{Crystallinity}

Starch structure was evaluated using X-Ray diffraction techniques. X-Ray diffraction patterns were recorded using a Shimadzu DX-1 X-Ray diffraction system (Shimadzu, Tokyo, Japan). All samples were analyzed between $2 \theta=10^{\circ}$ to $2 \theta=30^{\circ}$ using $\mathrm{K} \alpha \mathrm{Cu}$ radiation, $30 \mathrm{Kv}$ and $40 \mathrm{~mA}$ with a step size of $0.5 \%$ min. Crystallinity percent $(\%)$ was determined by deconvolution of the identified peaks (Colonna et al., 1987) using Origin 7.5 and expressed as the ratio of the sum of the areas corresponding to those peaks and the total area.

\subsubsection{Adsorption isotherms}

To obtain the adsorption isotherms, samples were dried in an oven (Selecta, Barcelona, Spain) at $40{ }^{\circ} \mathrm{C}$ under vacuum. The samples were introduced in desiccators (at $24^{\circ} \mathrm{C}$ ) using oversaturated solutions to equilibrate the water activity $\left(a_{w}\right)$ to their corresponding generated relative humidity/100. The salts and the respective $\mathrm{a}_{\mathrm{w}}$ used were $\mathrm{LiCl}: 0.113, \mathrm{CH}_{3} \mathrm{COOK}: 0.230, \mathrm{MgCl}_{2}$ : 0.330, $\mathrm{K}_{2} \mathrm{CO}_{3}: 0.430, \mathrm{Mg}\left(\mathrm{NO}_{3}\right)_{2}: 0.520, \mathrm{CuCl}_{2}: 0.680, \mathrm{NaCl}: 0.755$. The sample weights were 
controlled till a constant value $(\Delta \mathrm{m}< \pm 0.0005 \mathrm{~g})$ was reached, where the equilibrium was assumed. The equilibrium moisture content was determined in an oven at $105^{\circ} \mathrm{C} \pm 1{ }^{\circ} \mathrm{C}$ during 24 h. Experimental adsorption isotherms were fitted to Brunauer-Emmett-Teller (BET) (Eq. 1) (Brunauer et al., 1940) and Guggenheim-Andersen-de Boer (GAB) (Eq. 2) (Van den Berg et al., 1981) linearized models.

$$
\begin{aligned}
& \mathrm{w}_{\mathrm{e}}=\frac{\mathrm{w}_{\mathrm{o}} \cdot \mathrm{C} \cdot \mathrm{a}_{\mathrm{w}}}{\left(1-\mathrm{a}_{\mathrm{w}}\right) \cdot\left(1+(\mathrm{C}-1) \cdot \mathrm{a}_{\mathrm{w}}\right)} \\
& \mathrm{w}_{\mathrm{e}}=\frac{\mathrm{w}_{\mathrm{o}} \cdot \mathrm{C} \cdot \mathrm{K} \cdot \mathrm{a}_{\mathrm{w}}}{\left(1-\mathrm{K} \cdot \mathrm{a}_{\mathrm{w}}\right) \cdot\left(1+(\mathrm{C}-1) \cdot \mathrm{K} \cdot \mathrm{a}_{\mathrm{w}}\right)}
\end{aligned}
$$

Where: we, water content at equilibrium (g water/g dry solids); $\mathbf{a}_{\mathbf{w}}$, water activity; wo, monolayer value (g water/g dry solids); $\mathbf{C}$, constant related to monolayer sorption heat and $\mathbf{K}$, constant related to multilayer sorption heat.

\subsubsection{Glass transitions temperatures $(\mathrm{Tg})$}

To determine the glass transition temperature of the samples, a differential scanning calorimeter (DSC1, Mettler Toledo, Switzerland) was used. About 10-20 mg of each equilibrated sample was placed into DSC aluminum pans (ME-000267631, Mettler Toledo, Switzerland), sealed and analyzed. Each sample was analyzed in triplicate. The heating rate was $20^{\circ} \mathrm{C} / \mathrm{min}$ and the temperature range varied between 0 to $95^{\circ} \mathrm{C}$.

\subsubsection{Statistical Analysis}

Each assay was performed by triplicate. Analysis of variance was carried out using Statgraphics Plus 5.1 software (Statistical Graphics Corporation). The statistical differences among samples were determined using LSD test (Least Significant Difference). The accepted level of significance was $\mathrm{p}<0.05$. 


\section{Results and discussion}

Table 1 shows the composition of the samples in dry basis. Moisture content ranged between 9.9 and $12.7 \mathrm{~g}$ water/100 $\mathrm{g}$ of samples for extruded and non extruded samples, respectively. Crude protein and ash content did not change by different treatments. Lipid content (ether extract) of SR was lower than other non extruded samples, probably due to some germ losses during dehulling of soaked grains. Extrusion cooking process reduced ether extract respect to non extruded samples as it was shown by Percibaldi (2003). Moreover, some triglyceride hydrolysis was produced during extrusion cooking and fatty acids in the material could form complexes with amylose, making it more difficult to quantify crude fat (Ruiz-Ruiz et al., 2008).

Table 1 shows also FFA and TBARS of the samples. FFA decreased by $80 \%$ due to extrusion cooking in each whole grain rice product as compared with the brown rice without treatment (255.27 vs. 36.89; 28.84; 31.65 mg lauric ac./g for EBR, ESR and EGR, respectively). This can be due to the complex chemical reactions involving lipids in the extrusion cooking as it was shown by Percibaldi (2003). Also, $42 \%$ reduction of FFA was obtained after soaking process and $47 \%$ after germination process (147.51 and $135.77 \mathrm{mg}$ lauric ac./g, respectively), probably due to the losses of FFA into the soaking water.

The TBARS assay indicated that the results of processed samples by extrusion cooking were 2folds higher than non-extruded ones and the GR sample had higher values than the BR and SR. Nevertheless this increase in the TBARS assay would not be significant for the stability of the samples. Also, the development of new whole cereals based ingredients always implies an antioxidant agent addition.

Total fibre did not change by soaking or germination, but extrusion cooking decrease fibre content. Mercier (1993) found that the effect of cooking on the dietary fiber extrusion cooking and physiological properties depends on the extrusion cooking conditions. Generally, under high temperature and low screw speed and moisture content, a solubilization of insoluble dietary fiber is produced by increasing its breakdown. In soft or moderate conditions, fiber content does not 
change, but some components are solubilized. The shear forces can break the glycosidic linkages of the cellulose, degrading other components of the fiber, and increasing the soluble fiber at the expense of the insoluble one (Björck \& Asp, 1983). Drago et al. (2010) also observed a decrease of total dietary fibre in extruded whole grain maize.

Total starch content in the samples did not change by the treatments; the range was between 73.53-80.19 g/100 g d.b., similar to that reported by Juliano (1985). Significant differences among BR and the other raw samples (SR and GR) were due to BR was dehulled at the industry and SR and GR were dehulled at pilot plant. Available carbohydrates were higher in extruded samples because of macromolecular degradation, which depends on extrusion cooking parameters such as temperature, moisture and screw speed (Mercier, 1993).

Table 2 shows water solubility (WS) and water absorption (WA) of extruded and non extruded samples. WS and WA of non extruded samples were in the expected range, and there were no significant differences among them, indicating that soaking and germination did not modify these physical properties. However, extruded samples showed significant differences for both, WS and WA. WS is an indicator of starch granule disruption degree and was used to evaluate the degree of cooking (DC). Results showed that soaking and germination significantly affected DC attained during extrusion cooking of whole rice (EBR: 24.1 vs. ESR: 53.76 and EGR: 42.83 g/100g). The highest DC (highest WS) showed by ESR sample could be due to the acid treatment during soaking, which would allow starch granules have a higher disruption during extrusion cooking in comparison with extruded brown rice. On the other hand, germination process activates enzymatic systems, particularly proteases, which could disrupt protein network and favors thermo-mechanical effect on starch granules, giving higher values of WS. These results suggest that as pre-treatment, acid soaking allows obtaining a higher DC in extruded whole grain samples than germination.

Values of WA (Table 2) are in the range of those obtained for brown rice at similar extrusion cooking conditions in a previous work (González et al., 2013a). WA is directly related with WS 
until the maximum WA is reached. This maximum depends on the material and extrusion cooking conditions, but indicates a point from which the proportion of disrupt starch granules predominate in extruded sample, so that a further increment of DC would produce a decrease in WA (González et al., 2013b). This effect is shown in Figure 1. It was observed that the lowest value corresponded to ESR (5.81 ml/g of sample), indicating higher DC.

Table 2 shows the angles and intensity of crystalline peaks associated to starch crystal forms and crystallinity percentage in the studied samples, and Figure 2 shows the diffractogram patterns of non extruded and extruded samples corresponding to each treatment. Extrusion cooking destroys the organized crystalline structure either partially or completely, depending on the extrusion cooking variables such as moisture and shear (Colona et al., 1989). Native starch has a semicrystalline structure, since amylopectin in rice starch is organized in a monoclinic crystal lattice called A-type (Hoseney, 1986). In BR, SR, and GR the typical structure of native starch with the three picks around at $15.2^{\circ}, 17.4^{\circ}$ (with another at $18.3^{\circ}$ ) and $23^{\circ}$ were observed. The slightly higher value of crystallinity for SR in comparison with the other two non-extruded samples (BR and GR) would be attributed to an annealing effect caused by the heat treatment during soaking process ( $45^{\circ} \mathrm{C}$ during 24 hours) resulting in a more ordered crystalline structure of starch (Shandera \& Jackson, 1996). Extruded samples showed the disappearance of native crystalline structure and the formation of a new crystal with two picks $\left(2 \theta: 12^{\circ}\right.$ and $\left.18^{\circ}\right)$ called "E-type" crystal. According to Colonna et al. (1987), this structure corresponds to the typical amyloselipid complex. EBR showed a higher value of crystallinity than the other extruded samples, probably due to native starch remaining, which is in agreement with the lowest WS value in comparison with the other two extruded samples (ESR and EGR). Gonzalez et al (2013b) showed in their work that brown rice is not completely cooked at similar extrusion cooking conditions. Moreover, soaking and germination would induce structural starch changes which imply different behavior during extrusion cooking. 
Figure 3 shows water adsorption isotherms at $24{ }^{\circ} \mathrm{C}$ of all the samples. Adsorption data showed the typical sigmoid shape type II isotherms, frequently found in cereal foods. The adsorption region corresponding to the lowest $\mathrm{a}_{\mathrm{w}}$ represents monolayer adsorption, where most of the sites are charged or rich in polar groups, such as $\mathrm{OH}$ groups. In this region, water molecules are strongly bound on polar sites via hydrogen bonds (Van den Berg, 1986). As expected from the analysis of WS, WA and x-ray diffraction, extruded samples showed higher equilibrium moisture content than non extruded ones. These could be as a consequence of the disruption of the structure of components during extrusion cooking, mainly those of starch (amylose and amylopectin), which are broken to dextrin and also proteins (Donkor et al., 2012). The total effect of mechanical energy input is complex because it has at least two different roles. First, it promotes the disintegration of hydrated starch granules, protein bodies and lipid components, and mechanically mixes these fragments. Second, it raises the rate of chemical reactions, particularly the breaking of carbohydrate and protein chains (Kokini et al., 1992). The effect of extrusion cooking on water adsorption was enhanced by a previous grain germination process which would produce an increase in free amino and carboxylic groups probably because of the biosynthesis of new compounds (Kim et al., 2012).

The values of the BET and GAB parameters are shown in Table 3. In Figure 3 GAB model appear fitted to the experimental points of the isotherms. The monolayer water content $\left(\mathrm{w}_{\mathrm{o}}\right)$ estimated by GAB was higher than that obtained by BET. Timmermann (2003) attributed inequality in monolayer water values to the physical and mathematical nature of the models. $\mathrm{w}_{\mathrm{o}}$ represents the moisture content at which the water is attached to each polar and ionic groups. BET monolayer water content value is more widely accepted, as the BET model has a true physical sense in the range of low $\mathrm{a}_{\mathrm{w}}$, related to the adsorption theory, while the GAB model is a more empirical one that provides accurate prediction over the water activity range up to 0.75 . Theoretically, both methods should provide similar monolayer value. However, as BET isotherm 
fitted well in the range of water activities of 0 to 0.43 , adequate range for the calculation of parameters $\mathrm{w}_{\mathrm{o}}$ and $\mathrm{C}$ for extruded products, this monolayer water content would be preferred.

According to BET, extruded samples showed higher $\mathrm{w}_{0}$ than the corresponding sample without extrusion cooking, and GR and EGR have higher $\mathrm{w}_{0}$ and $\mathrm{C}$ values, meaning that these samples would have higher values of heat of water interaction than the other samples. For GAB, SR showed the lowest value and GR the highest one for $\mathrm{w}_{0}$ in extruded and non-extruded samples.

In both models, $\mathrm{C}$ values were higher in extruded samples because they adsorbed more water, increasing heat of sorption. As it was mentioned above, this effect could be due to the extrusion cooking process that breaks some linkages and generates larger available surface area and polar groups for adsorption.

Gonzalez et al. (2004) showed that expanded product based on corn flours would lose their crispness when $\mathrm{a}_{\mathrm{w}}$ exceed 0.33 (around 0.065 moisture content dry basis). Although the moisture content of corn extruded product were lower than that of extruded whole rice product (Figure 3), our results would suggests that in the case of extruded whole rice products stored at the same moisture content (around 5\%), those samples with higher $\mathrm{w}_{0}$ will have lower $\mathrm{a}_{\mathrm{w}}$, thus EGR will keep the crispness properties in a wider range of moisture.

In spite of the structural changes in starch fraction caused by the different treatments discussed above, no changes on Tg values were observed, neither by the treatment nor by the change of water content on samples. Figure 4 shows the obtained thermograms of the different samples at the same water content. As can be seen, this figure allows evaluating the onset, midpoint, endpoint of $\mathrm{Tg}$ and $\Delta \mathrm{Cp}$. Table 4 shows midpoint $\mathrm{Tg}$ and $\Delta \mathrm{Cp}$ for $\mathrm{BR}$ and EBR samples at different water contents.

Despite no differences in Tg were observed, a difference in $\Delta \mathrm{Cp}$ between BR and EBR can be observed. These would indicated that water-solid energy of interaction is higher in extruded sample (EBR) in comparison with non-extruded one (BR), being in agreement with the results of C values discussed above. 
Recent available information on the evaluation of $\mathrm{Tg}$ of whole grain flour is poor (Herawat et al., 2014). Perdon et al. (2000) studied the glass transition of brown rice kernels of different type of rice using three methods, DSC, TMA (thermal mechanical analysis) and DMA (dynamic mechanical analysis). These authors showed that $\mathrm{Tg}$ was not affected by the changes in moisture content in the range used in our study (around 4 to $17 \mathrm{~g}$ of water/100 $\mathrm{g}$ of sample). Previous studies showed that DSC was not sensitive enough to detect thermal transition in rice samples. Sun et al. (2002) reported that DSC was not sufficiently sensitive to accurately measure rice kernel $\mathrm{Tg}$ due to rice kernel being a partially crystalline/partially amorphous. The composition of the samples would contribute to the poor sensitivity for $\mathrm{Tg}$ detection. If most of the carbohydrates, proteins and fiber are non-soluble, especially in the case of non-extruded samples (with a very low WS) or non-compatible with water (may be in the case of the extruded samples), and appear in the rice defining its own phase, a low amount of amorphous phase is expected to be formed. These, together with the low quantity of sample that can be analyzed by DSC, justify the low sensitivity observed.

The fact that no changes on $\mathrm{Tg}$ were observed, neither by the change of moisture for BR and EBR nor by any of the treatment used in this study, prevent us to make any interpretation about phase transition behavior and structural changes. On the other hand, breakage of starch and proteins during extrusion, especially in grains previously germinated, increases the hygroscopicity of the samples. The newly formed compounds would make all the samples equally sensitive to the glass transition. From this point of view, the evolution of all of them during storage will be of the same order; suggesting that the structure of extruded whole rice would be stable in a wider range of moisture content. Moreover the glass transition temperature is high enough (about $50^{\circ} \mathrm{C}$ ) to ensure the stability of the product.

\section{Conclusions}

Soaking and germination treatments applied to rough rice increase the degree of cooking attained during extrusion cooking respect to the extruded brown rice. This effect was higher for soaked 
samples than for germinated ones. Soaking of rough rice also produced an annealing effect in starch structure. Extruded samples showed higher equilibrium moisture content as a consequence of structure components disruption (starch and proteins) during extrusion cooking. The effect of extrusion cooking on increasing equilibrium moisture would be enhanced by a previous grain germination process. The $\mathrm{Tg}$ of the samples was not affected neither by the water content no by the process.

Soaking, germination and extrusion processes could be used at industrial scale because they are low cost, simple and efficient methods for producing physicochemical changes in cereals. Modified WG flours could be used in the production of low phytate content expanded products (snacks) or precooked flours for development of WG foods.

\section{Acknowledgment}

This work was partially financed by ANPCYT (PICT 1105) and ERASMUS MUNDUS ACTION 2 ARCOIRIS Fellowship

\section{References}

Albarracín, M., González, R.J. \& Drago, R. S. (2015). Soaking and extrusion effects on physicochemical parameters, phytic acid, nutrient content and mineral bio-accessibility of whole rice grain. International Journal of Food Sciences and Nutrition, 66, 2, 210-215.

AOAC, Official Methods of Analysis, Association of Official Analytical Chemists, Arlington, Tex, USA, 16 edition, 1999.

Björck, I. \& Asp, N.G. (1983). The effects of extrusion cooking on nutritional value- A literature review. Journal of Food Engineering, 2, 281-308.

Brunauer, S., Deming, L.S., Deming, W.E. \& Teller, E. (1940). On a theory of the van de Waals adsorption of gases. Journal of American Chemistry Society, 62, 1723-1732.

Colonna, P., Buleon, A. \& Mercier, C. (1987). Chapter 4 "Physically modified starches" In Clinical Reports on Applied Chemistry, volume 13, Starch: Properties and Potential. Ed. by T. Galliard. Published for the Society of Chemical Industry by John Wiley \& Sons. 
Colonna, P., Tayeb, J. \& Mercier, C. (1989). Charpter 9: "Extrusion cooking of starch and starchy products" in Extrusion Cooking. Ed. by Mercier C., Linko P., Harper J.M. (pp 247-319). Published by the American Association of Cereal Chemist, Inc. St Paul, Minnesota, USA.

Donkor, O.N., Stojanovska, L., Ginn, P., Ashton, J. \& Vasiljevic, T. (2012). Germinated grains Sources of bioactive compounds. Food Chemistry, 135, 950-959.

Drago, S., Zuleta, A., De Greef, M., Torres, R., González, R. J., Chel Guerrero, L. \& Betancur Ancona, D. (2010). Disponibilidad de minerales de extrudidos elaborados con granos enteros de maíz y/o leguminosa (Phaseolus vulgaris). En: Utilización de recursos naturales tropicales para el desarrollo de alimentos. Ed.: DA. Betancur Ancona, LA. Chel Guerrero, AF. Castellanos Ruelas. (cap16, pp. 208-223). Ediciones de la Universidad Autónoma de Yucatán. Mérida, Yucatán, México, ISBN: 978-607-7573-77-7.

González, R. J.; Torres, R. L. \& De Greef, D. M. (2002). Extrusión-Cocción de Cereales Boletín da Sociedade Brasileira de Ciencia e Tec de Alimentos (sbCTA). Campinas. 36 (2), 83 136.

González, R. J.; De Greef, D. M., Torres, R. L., Borrás F. S. \& Robuti J. (2004). Effects of endosperm hardness and extrusion temperature on properties of products obtained with grits from two commercial maize cultivars. Lebensmittel-Wissenschaft \& Technologie, 37, 193-198.

González, R. J., Pastor-Cavada, E., Vioque, J., Torres, R. L., De Greef, D. M. \& Drago S. R. (2013a). Extrusion conditions and amylose content affect physicochemical properties of extrudates obtained from brown rice grains. International Journal of Food Science, vol. 2013, Article ID 584148, 8 pages.

González, R. J., Drago, S. R., Torre, R. L. \& De Greef, M. D. (2013b). Extrusion cooking of cereal-based products in engineering aspects of cereals and cereal-based products, in Engineering Aspects of Cereal and Cereal-Based Products. (Chapter 12, pp. 269-291). Edit by Pinho Ferreira Guiné, Paula Maria dos Reis Correia. CRC Press Taylor \& Francis Group. 
Herawat, H., Kusnandar, F., Adawiyah, D.R., Budijanto, S. \& Rahman, M.S. (2014). Thermal characteristics and state diagram of extruded instant artificial rice. Thermochimica Acta, 593, $50-57$.

Hoseney, R. C. (1986). Cereal Starch, Charpter. 2. Principles of Cereal and Technology. American Association of Cereal Chemist.

Jones, J. M. \& Engleson J. (2010). Whole grain benefits and challenges. Annual Review of Food Science and Technology, 1, 19-40.

Juliano, B. O. (1985). Rice: Chemistry and Tecnhology. (Second Edition). St. Paul, Minnesota, USA.

Kim, H. Y., Hwang, I. G., Kim,T. M., Woo, K. S., Park, D. S., Kim, J. H., Kim, D. J., Lee, J., Lee, Y. R. \& Jeong, H. S. (2012). Chemical and functional components in different parts of rough rice (Oryza sativa L.) before and after germination. Food Chemistry, 134, 288-293.

Lowry, R. \& Tinsley, Ian. (1976). J. Rapid Colorimetric Determination of Free Fatty Acids. J. Am. Oil Chem. Soc. 7, 470-472.

Kokini, J.L., Ho, C. \& Karwe, M.V. (1992) Molecular restructuring and complexation during extrusion of cornmeal. In Food Extrusion Science and Technology, ed. Marcel Dekker, Inc., New York, pp. 437-447.

Matveev, Y. I.; Grinberg V. Y. \& Tolstoguzov V. B. (2000). The plasticizing effect of water on proteins. polysaccharides and their mixtures. Glassy state of biopolymers: food and seeds. Food Hydrocolloids, 14 (5), 425-437.

Mercier, C. (1993) Nutritional appraisal of extruded foods. International Journal of Food Sciences and Nutrition, 44 (1), S45-S53.

Percibaldi, N.M. (2003). Tesis de Magíster en Ciencias y Tecnología de Alimentos. "Variación de la composición lipídica en germen y endospermo de variedades de maíz argentino y su asociación con el proceso de extrusión”. UNL-FIQ-ITA. 
Perdon, A., Siebenmorgen, T.J. \& Mauromoustakos, A. (2000). Glassy state transition and rice drying: development of a brown rice state diagram. Cereal Chemistry, 77, 708-713.

Roos, Y. \& Karel, M. (1991). Plasticizing effect of water on thermal behavior and crystallization of amorphous food models. Journal of Food Science, 56, 38-43.

Ruiz-Ruiz, J, Martínez-Ayala, A., Drago, S., González, R., Betancur-Ancona, D. \& ChelGuerrero, L. (2008). Extrusion of a hard-to-cook bean (Phaseolus vulgaris L.) and quality protein maize (Zea mays L.) flour blend. LWT - Food Science and Technology, 41, 1799-1807.

Shandera, D.L. \& Jackson D.S. (1996). Effect of Corn wet-milling conditions (sulfur dioxide, latic acid and steeping temperature) on starch functionality. Cereal Chemistry, 73 (5), 632-637.

Siu, G. M. \& Draper, H. H. (1978). A survey of malonaldehyde content of retail meats and fish. Journal of Food Science 43, 1147-49.

Sun, Z, Yang, W, Siebenmorgen, T., Stelwagen, A. \& Cnossen A. (2002). Thermomechanical Transitions of Rice Kernels. Cereal Chemistry, 79 (3), 349-353.

Timmermann, E. O. (2003). Multilayer sorption parameters: BET or GAB values? Colloids and Surfaces A: Physicochemical and Engineering Aspects, 220, 235-260.

Tovar, J., Björck, I. \& Asp, N. G. (1990). Starch content and alpha-amylolysis rate in precooked legumes flours. Journal of Agricultural and Food Chemistry, 38(9), 1818-1823.

Van den Berg, C. (1986). In: MacCarthy, D. (Ed.), Concentration and Drying of Foods. Elsevier Applied Sciences, London, pp. 11-35. 


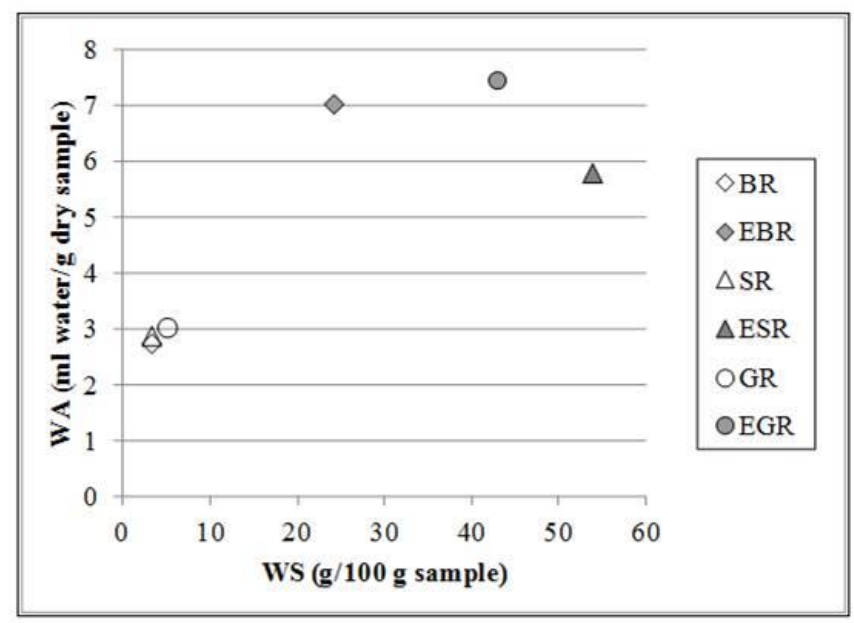

Figure 1: WA and WS relationship of the non extruded and extruded samples. BR: brown rice; EBR: extruded brown rice; SR: soaked rice; ESR: extruded soaked rice; GR: germinated rice; EGR: extruded germinated rice.

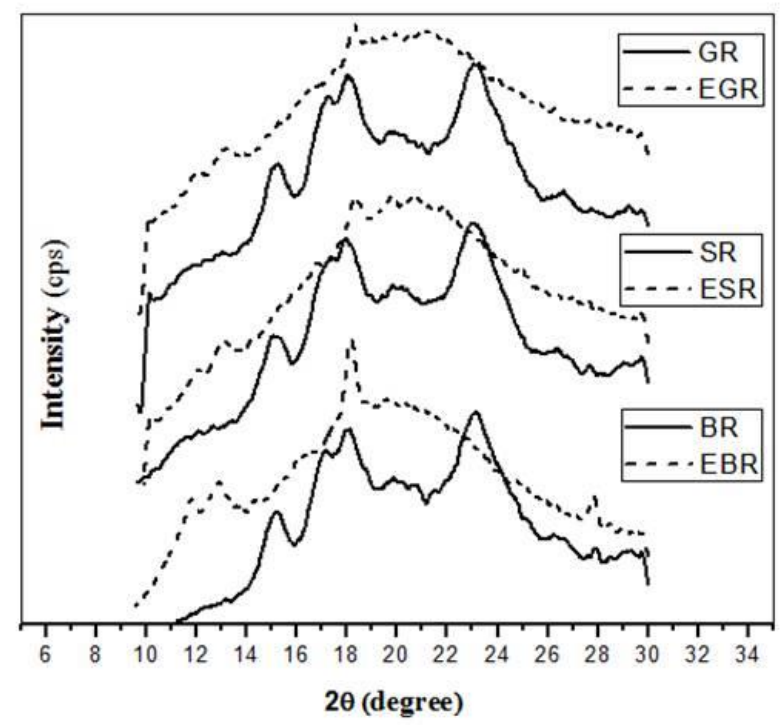

Figure 2: X-ray diffraction patterns of Brown Rice (BR), Extruded Brown Rice (EBR) Soaked Rice (SR), Extruded Soaked Rice (ESR), Germinated Rice (GR) and Extruded Germinated Rice (EGR) samples. 


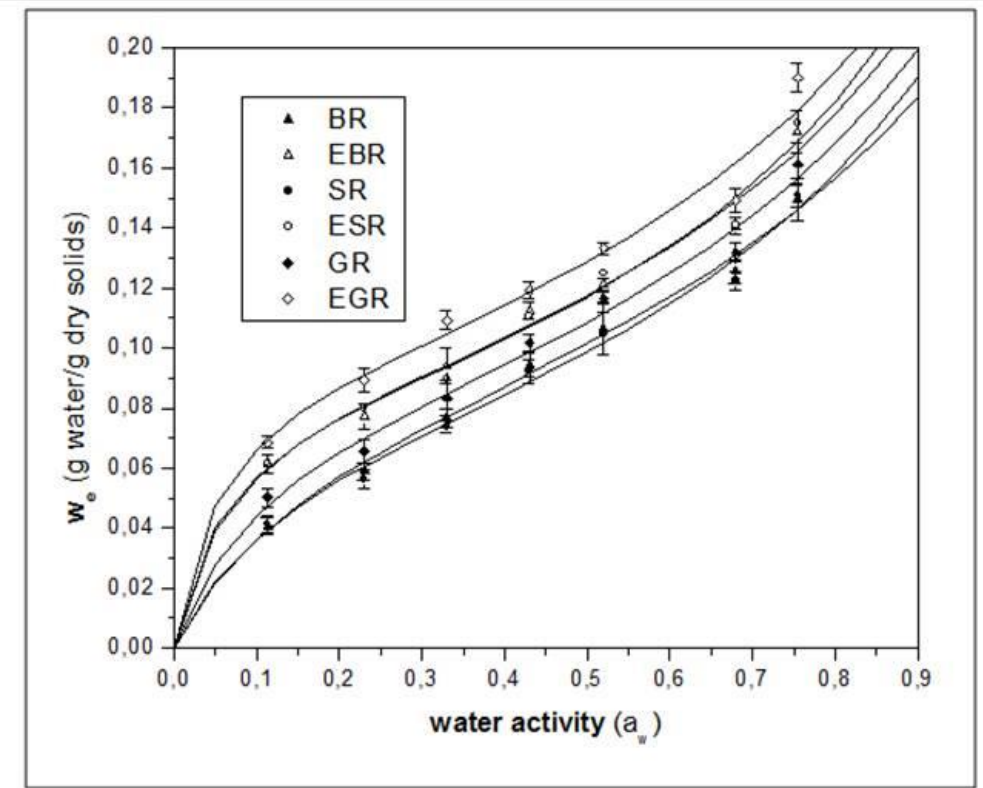

Figure 3: Adsorption isotherms of Brown Rice (BR), Extruded Brown Rice (EBR), Soaked Rice (SR), Extruded Soaked Rice (ESR), Germinated Rice (GR) and Extruded Germinated Rice (EGR) at $24^{\circ} \mathrm{C}$. Experimental points and GAB fitted model (lines).|

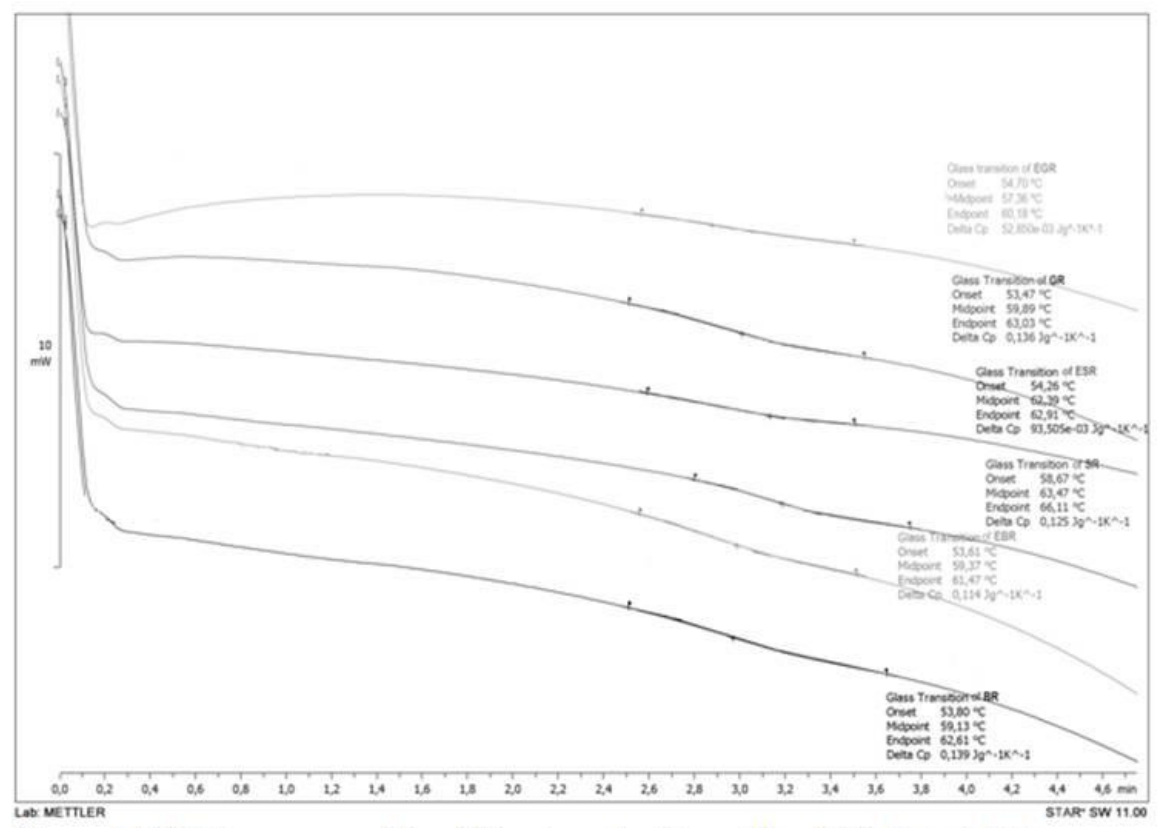

Figure 4: DSC thermograms of the different samples Brown Rice (BR), Extruded Brown Rice (EBR), Soaked Rice (SR), Extruded Soaked Rice (ESR), Germinated Rice (GR) and Extruded Germinated Rice (EGR) at the same moisture content $(6 \mathrm{~g}$ water $/ 100 \mathrm{~g}$ dry matter). 
Table 3: Model parameters of water adsorption isotherms (BET and GAB) of Brown Rice (BR), Extruded Brown Rice (EBR), Soaked Rice (SR), Extruded Soaked Rice (ESR), Germinated Rice (GR) and Extruded Germinated Rice (EGR).

\begin{tabular}{|c|c|c|c|c|c|c|}
\hline Models & BR & EBR & SR & ESR & GR & EGR \\
\hline BET & & & & & \\
\hline wo (g water/g dry solids) & 0.0601 & 0.0666 & 0.0578 & 0.0642 & 0.0620 & 0.0714 \\
C & 11.238 & 32.729 & 12.047 & 47.436 & 17.721 & 69.681 \\
$\mathrm{R}^{2}$ & 0.9987 & 0.9995 & 0.9947 & 0.9974 & 0.9976 & 0.9901 \\
\hline GAB & & & & & & \\
C w $_{\mathrm{o}}$ (g water/g dry solids) & 0.084 & 0.084 & 0.076 & 0.081 & 0.082 & 0.091 \\
$\mathrm{~K}$ & 9.802 & 23.042 & 10.712 & 25.154 & 13.872 & 29.156 \\
$\mathrm{R}^{2}$ & 0.637 & 0.680 & 0.693 & 0.710 & 0.673 & 0.671 \\
\hline
\end{tabular}


Table 4: Glass transition temperature (midpoint TG and $\Delta \mathrm{Cp}$ ) of $\mathrm{BR}$ and EBR samples equilibrated at different water activities (0.113-0.755).

\begin{tabular}{|c|c|c|c|c|c|c|}
\hline \multirow{2}{*}{$\begin{array}{l}\text { Water } \\
\text { activity }\end{array}$} & \multicolumn{3}{|c|}{ BR Samples } & \multicolumn{3}{|c|}{ EBR Samples } \\
\hline & $\begin{array}{c}\text { Water content } \\
\text { (g water /100 g sample) }\end{array}$ & $\begin{array}{l}\mathbf{T g} \\
\left({ }^{\circ} \mathrm{C}\right)\end{array}$ & $\underset{(\mathrm{J} / \mathrm{g} \cdot \mathrm{K})}{\Delta \mathbf{C p}}$ & $\begin{array}{c}\text { Water content } \\
\text { (g water /100 g sample) }\end{array}$ & $\begin{array}{l}\mathbf{T g} \\
\left({ }^{\circ} \mathrm{C}\right)\end{array}$ & $\underset{(\mathrm{J} / \mathrm{g} . \mathrm{K})}{\Delta \mathbf{C p}}$ \\
\hline 0.113 & 4.06 & 58.05 & 0.098 & 6.15 & 59.65 & 0.130 \\
\hline 0.230 & 5.89 & 56.86 & 0.131 & 7.71 & 57.82 & 0.126 \\
\hline 0.330 & 7.66 & 60.94 & 0.154 & 9.40 & 58.16 & 0.203 \\
\hline 0.430 & 9.44 & 62.15 & 0.165 & 11.24 & 59.32 & 0.166 \\
\hline 0.520 & 10.65 & 59.77 & 0.180 & 12.14 & 59.74 & 0.199 \\
\hline 0.680 & 12.57 & 60.01 & 0.210 & 14.06 & 59.70 & 0.263 \\
\hline 0.755 & 14.95 & 59.16 & 0.182 & 17.20 & 59.13 & 0.412 \\
\hline
\end{tabular}

3

4 
Table 1. Composition, Free Fatty Acids (FFA) content and TBA reactive substances (TBARS) of Brown Rice (BR), Extruded Brown Rice (EBR), Soaked Rice (SR), Extruded Soaked Rice (ESR), Germinated Rice (GR) and Extruded Germinated Rice (EGR).

\begin{tabular}{|c|c|c|c|c|c|c|c|c|}
\hline Samples & $\begin{array}{c}\text { Crude } \\
\text { Proteins } \\
\text { (g/100 g d.b) }\end{array}$ & $\begin{array}{c}\text { Lipids } \\
\text { (ether } \\
\text { extract) } \\
\text { (g/100g d.b) }\end{array}$ & $\begin{array}{l}\text { Total } \\
\text { Fiber } \\
(\mathrm{g} / 100 \mathrm{~g} \\
\text { d.b) }\end{array}$ & $\begin{array}{c}\text { Ashes } \\
\text { (g/100g d.b) }\end{array}$ & $\begin{array}{c}\text { Total } \\
\text { Starch } \\
(\mathrm{g} / 100 \mathrm{~g} \mathrm{~d} . \mathrm{b})\end{array}$ & $\begin{array}{c}\text { Available } \\
\text { Carbohydrates* } \\
\text { (g/100 g d.b) }\end{array}$ & $\begin{array}{c}\text { FFA } \\
(\mathrm{mg} \mathrm{Lauric} \\
\text { acid/g) }\end{array}$ & $\begin{array}{c}\text { TBA reactive } \\
\text { substances } \\
(\mu \mathrm{mol} / \mathrm{g})\end{array}$ \\
\hline BR & $6.97 \pm 0.15^{\mathrm{a}}$ & $1.88 \pm 0.01^{\mathrm{a}}$ & $5.5 \pm 0.6^{\mathrm{a}}$ & $1.11 \pm 0.01^{\mathrm{a}}$ & $77.74 \pm 1.13^{\mathrm{b}}$ & 84.54 & $255.27 \pm 12.24^{\mathrm{a}}$ & $2.77 \pm 0.46^{\mathrm{d}}$ \\
\hline EBR & $6.63 \pm 0.20^{\mathrm{a}}$ & $0.46 \pm 0.19^{c}$ & $3.9 \pm 0.3^{b}$ & $0.99 \pm 0.01^{\mathrm{a}}$ & $76.94 \pm 0.30^{b}$ & 86.60 & $36.89 \pm 2.30^{c}$ & $7.83 \pm 0.20^{c}$ \\
\hline SR & $6.48 \pm 0.10^{\mathrm{a}}$ & $1.09 \pm 0.02^{\mathrm{b}}$ & $5.7 \pm 0.7^{\mathrm{a}}$ & $0.98 \pm 0.11^{\mathrm{a}}$ & $80.19 \pm 0.92^{\mathrm{a}}$ & 85.75 & $147.51 \pm 7.99^{b}$ & $3.74 \pm 0.13^{\mathrm{d}}$ \\
\hline ESR & $6.37 \pm 0.12^{\mathrm{a}}$ & $0.73 \pm 0.04^{\mathrm{c}}$ & $3.3 \pm 0.3^{b}$ & $1.03 \pm 0.07^{\mathrm{a}}$ & $76.15 \pm 0.26^{b}$ & 88.21 & $28.84 \pm 2.01^{\mathrm{c}}$ & $7.07 \pm 0.52^{c}$ \\
\hline GR & $6.65 \pm 0.10^{\mathrm{a}}$ & $1.63 \pm 0.20^{\mathrm{a}}$ & $5.7 \pm 0.6^{a}$ & $1.20 \pm 0.30^{\mathrm{a}}$ & $79.37 \pm 0.31^{\mathrm{a}}$ & 84.82 & $135.77 \pm 4.06^{\mathrm{b}}$ & $9.89 \pm 0.32^{b}$ \\
\hline EGR & $6.70 \pm 0.40^{\mathrm{a}}$ & $0.47 \pm 0.15^{\mathrm{c}}$ & $3.2 \pm 0.4^{\mathrm{b}}$ & $1.23 \pm 0.06^{\mathrm{a}}$ & $73.53 \pm 0.77^{\mathrm{c}}$ & 87.24 & $31.65 \pm 2.00^{c}$ & $13.11 \pm 0.1^{\mathrm{a}}$ \\
\hline
\end{tabular}

Mean values \pm standard deviations $(n=3)$; Different letters in the same column mean significant differences between samples $(\mathrm{p}<0.05)$

*Available carbohydrate content was calculated by difference. 
Table 2. Water absorption (WA), Water solubility (WS), angles and intensity (cps $10^{-3}$ ) of

2 crystalline peaks (20) and crystallinity value (\%) of Brown Rice (BR), Extruded Brown Rice 3 (EBR), Soaked Rice (SR), Extruded Soaked Rice (ESR), Germinated Rice (GR) and Extruded Germinated Rice (EGR).

\begin{tabular}{|c|c|c|c|c|}
\hline $\begin{array}{l}\text { Parameter/ } \\
\text { Samples }\end{array}$ & $\begin{array}{c}\text { WS } \\
\text { (g sample/100 g } \\
\text { sample) }\end{array}$ & $\begin{array}{c}\text { WA } \\
\text { (ml of water/g } \\
\text { dry sample) }\end{array}$ & 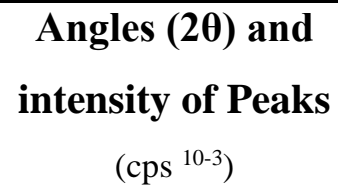 & $\begin{array}{c}\text { Crystallinity } \\
\text { Value } \\
(\%)\end{array}$ \\
\hline BR & $3.18 \pm 0.05^{\mathrm{a}}$ & $2.77 \pm 0.15^{\mathrm{a}}$ & $\begin{array}{c}15.17^{\circ}(3.18) \\
17.65^{\circ}(9.88) \\
23.26^{\circ}(17.13)\end{array}$ & $30 \pm 2^{a}$ \\
\hline EBR & $24.1 \pm 0.9^{\mathrm{b}}$ & $7.04 \pm 0.06^{\mathrm{c}}$ & $\begin{array}{c}12.30^{\circ}(14.38) \\
18.17^{\circ}(2.11)\end{array}$ & $16 \pm 2^{b}$ \\
\hline SR & $3.17 \pm 0.03^{\mathrm{a}}$ & $2.90 \pm 0.13^{\mathrm{a}}$ & $\begin{array}{c}15.06^{\circ}(3.03) \\
17.70^{\circ}(13.88) \\
23.17^{\circ}(15.66)\end{array}$ & $33 \pm 2^{c}$ \\
\hline ESR & $53.76 \pm 2.0^{\mathrm{d}}$ & $5.81 \pm 0.21^{b}$ & $\begin{array}{l}12.71^{\circ}(3.10) \\
18.33^{\circ}(0.84)\end{array}$ & $4 \pm 2^{\mathrm{d}}$ \\
\hline GR & $4.98 \pm 0.19^{\mathrm{a}}$ & $3.05 \pm 0.20^{\mathrm{a}}$ & $\begin{array}{l}15.01^{\circ}(2.32) \\
17.73^{\circ}(9.08) \\
23.17^{\circ}(15.99)\end{array}$ & $30 \pm 2^{\mathrm{a}}$ \\
\hline EGR & $42.83 \pm 0.20^{c}$ & $7.47 \pm 0.11^{\mathrm{d}}$ & $\begin{array}{l}12.81^{\circ}(3.59) \\
18.29^{\circ}(0.82)\end{array}$ & $4.4 \pm 1.5^{\mathrm{d}}$ \\
\hline
\end{tabular}

Mean values \pm standard deviations $(\mathrm{n}=3)$.

Different letters in the same column mean significant differences between samples $(p<0.05)$ 